\title{
The Scheduling Decision of a Refinery: The Decision Maker in Search of Conflict Resolution
}

\author{
Thaís Spiegel (Corresponding author) \\ Professor, Industrial Engineering Department, Rio de Janeiro State University \\ São Francisco Xavier street, 524 / hall 5030-A, Rio de Janeiro, 20550-900, Brazil \\ Tel: 55-21-2587-7156_E-mail: thais.spiegel@uerj.br \\ Heitor Mansur Caulliraux \\ Professor, Production Engineering Program, Rio de Janeiro Federal University \\ PO Box 68.507, Rio de Janeiro, Brazil \\ Tel: 55-21-2562-7415Ｅ-mail: heitor.caulliraux@gpi.ufrj.br
}

Received: May 23, 2015 Accepted: May 27, 2015 Published: May 28, 2015

doi:10.5296/bmh.v3i1.7670ＵRL: http://dx.doi.org/10.5296/bmh.v3i1.7670

\begin{abstract}
Refineries typically gather a set of activities that are complex and dynamic. Adding to the complexity of the refining process, there is also great freedom in refinery operations, multiple possible arrangements to convert certain oils in derivatives. In this context, this paper focuses on the decision-making processes that lead refiners of an integrated oil company in their day to day. As decision making, the text refers to a process that always brings a kind of conflict resolution, in which conflicting goals have to be negotiated and reconciled. The object of analysis is inserted in hierarchical decision-making processes, e.g. a breakdown process, which begins with a comprehensive evaluation and then divides the decision into ever smaller and more defined elements so that they are interdependent. The output at an aggregated level is then input in the next detailed level. In each of the hierarchical levels, the decision-making is the result of a problem presented in a certain context to a decision maker. This decision maker will be responsible for the direction of the refinery production in which he/she is allocated. The programmer of each refinery have general guidelines that should be considered, albeit non-explicitly or non-definable way, these take the form of criteria in some cases of technical origin and in other situations derived from the business. Given these aspects, this article presents a critical and analytical view in the face of dilemmas that emerge before the
\end{abstract}


search of the decision makers to converge scheduling production considering both set of criteria.

Keywords: decision maker, decision making, scheduling, refinery, trade-off 


\section{Introduction}

Like most of the oil refining companies, the Company analyzed in this paper is an integrated oil company that has a variety of interests, from exploration and production to marketing and distribution of oil. Within these organizations, refineries work under the direction of a head office. The head office negotiates long and short term contracts to buy oil and derivatives, while the set of refineries converts oil into derivatives, so that they are sold as final products.

The refinery itself usually works within the overall framework of the organization to maximize the company's profitability. The aim of refining within the supply chain sector is to produce quantities and qualities of required intermediates and finished products in such a way that it maximizes profit while respecting the legal and social restrictions. This makes refining an extremely complex and dynamic activity. Adding to the complexity of the refining process, there is also great freedom in refinery operations, multiple possible arrangements to convert certain oils in derived products.

The main trends are (Shell, 2010): (1) The implementation of a mindset that guides the "mix and gets rid of what was produced" to that which guides to the "production of what may be mixed" - that is, rather than a system that pushes, refining is a system in line with the real demands of the market; (2) the atomization of the product portfolio: from "integrated border management" to a "managed portfolio of products" - that is, seeking to exploit in the pool of derivatives those currents that are more profitable, relegating the other products a secondary (or even undesirable) position; (3) an intensification of international trade in derivatives and intermediates as distribution costs decrease and trade patterns are established; and (4) a ripening production technology, although complex. Thus, differences between refineries and between corporations become more unlikely.

According to Sahdev et al. (2004), oil refining in the new millennium remains an extremely competitive business. The authors emphasize that planning refining is the basis for business decisions with greater impact on the profitability of the refinery.

For this plan to succeed, it is essential that it be organic and dialogues with management procedures actually used by decision makers. Such processes must incorporate the appropriate forms of use of mathematical programming, both in terms of provision of inputs as the absorption and application of its results, reconciling it with the realities of the organization and its concrete infrastructural and operational limits. In this context, this paper deals with the managerial decision making process of scheduling the refineries.

To address this management process of high impact on the refining performance, this article first presents the theoretical framework of decision theory to provide understanding of the variables that comprise the problem, the context and the decision maker. The paper has an analysis focused on the role of the decision maker - human agent upon which rests the responsibility for the decision. The main technical and corporate guidelines governing the choice of programmers in the analyzed Company's refineries are presented. The paper seeks to establish a critical and analytical view in the face of trade-offs that emerge before the search of the decision makers converge into programming production that simultaneously 
meets the criteria set.

\section{Decision-Making Process: The Decisions of Production Scheduling of a Refinery}

Initially, the process of decision-making, the outcome of the process, i.e., the decision itself, should be distinguished. While the former refers to efforts to make a choice (Svenson, 1996), the other refers to the choice of a particular situation. There is a set of variations on how to conceptualize the decision-making process (Hastie \& Pennington, 1995). They will be discussed in the following paragraphs.

Ofstad (1961, p. 5 apud Harrison, 1999, p. 4) proposes three alternative definitions for decision making. According to the author, saying that someone made a decision means that (1) the person started a series of behavioral reactions in favor of something, or (2) the person has directed his/her mind to perform a certain action he/she has no doubt should be carried out. However, perhaps the most "common" use of the term "make a decision" means (3) to make a judgment about what to do in a given situation, after having deliberated on some alternative courses of action.

In the words of Simon (1960, p. 1), “decision making comprises three major phases: finding occasions to make the decision, finding possible courses of action, and choose between courses of action." Consistent with the third view presented by Ofstad and the conception of Simon, Hastie \& Pennington (1995) argue that the essence of the conceptual definition proposed is that decision-making involves the deliberate choice of a course of action with the intention of producing the maximum of a desired result.

There are many subtle variations on this basic definition. Initially analyzing the condition of deliberation, i.e. decision making as a process of choosing one option or course of action from a set of alternatives. The conception of Corrado et al., (2008), that a decision occurs when an organism faced with several discrete options, evaluates the merits of each of them, and selects one of the options to pursue. Berthoz (2006) considers decision-making as an act by which the brain, faced with several solutions to identify an object, guide a movement, or solve a problem, "cuts" in favor of one solution over another. Although some theorists do not think that the condition of deliberation is necessary, this paper follows the proposition of Berthoz (2006) and Corrado et al. (2008).

Note that by accepting the decision between alternatives, the decisions to conscious processes are not restricted. This research is understood as decision making of conscious and unconscious choices of humans. Thus, it does not agree with Shull et al, (1970, p. 31 apud Harrison, 1999, p. 4) that define the process of decision making as "a conscious human process, involving individual and social phenomena, based on factual and value assumptions, including the choice of behavioral activity before a set of alternatives with the intention of moving toward a desired state."

Although the reference to the conscious human process is not adopted in the understanding of this study, the definition of Shull et al. (1970) presents interesting elements. In particular, the mention to assumptions adopted by the decision maker and the existence of desirable states of them. The concept of the desired situation is also present in Harrison (1999), when referring 
to a decision as a moment in an ongoing process of evaluating alternatives to achieve a goal, in which expectations over a particular course of action to compel the decision maker to select the one that most closely reaches the goal.

In short, all these definitions converge to a common set of components: a set of choice options or courses of action, a backdrop of controllable and uncontrollable events that determine the outcome of the combination of events and actions that occur, and are a consequence of the objective outcome (Hastie \& Pennington, 1995).

If the decision is always a kind of conflict resolution, in which conflicting goals have to be negotiated and reconciled, it can be said that this resolution is strongly dependent on the problem at hand, the context and individual factors that make the activity an "enigma" and hinder the identification of regular patterns, liable to generalization (Svenson 1996, p. 252). Aligned with the vision of Ola Svenson, Payne et al. (1993) argue that there are three classes of core factors that influence a particular decision: the decision problem characteristics, characteristics of the person and characteristics of the social context.

Different decisions require different times to take effect, given by their different inertia. In organizations, these sub-horizons are generally divided into long term, medium term and short term (Corrêa, 2001). The Hierarchical Planning is a breakdown process, which begins with a comprehensive evaluation, and then divides the plane into smaller and more specific elements, so that they are interdependent. The output at an aggregated level is then input in the next detailed level.

The Hierarchical Planning that is object of this paper begins at the strategic level, with the decision of the Company's Aggregated Plan of Oil Refining. From this plan, within each refinery and at a tactical level, the Production Plan is elaborated with a two-month horizon. This decision is at the tactical level of the Planning. At the operational level, the schedules with daily and weekly horizon are elaborated, ending the decision-making process.

\subsection{The Problem and the Context}

When analyzing the factors that comprise the decision-making, there is initially the problem and the context in which it is, i.e. the production system. One problem varies according to its structure, stability and understanding (Yang, 2003). Its importance, complexity or urgency influence the decision to be made (Bronner, 1993). From the perspective of the problem, Bronner (1993) suggests that decision-making is confronting a task with specific management.

Payne et al. (1993, p. 34) indicate that the complexity of decision-making is influenced by several variables such as the number of alternatives available, the number of attributes or dimensions of information on which the alternatives vary, and time pressure. Intrinsic characteristics of the context in which the decision problem is presented.

The decision making process is highly influenced by the outside environment, whether economically, socially or politically, through regulations, whether scientific or technological, through trends. In addition, there is the internal environment interfering heavily in the 


\section{Macrothink}

decision-making process, through strategies, policies, guidelines and standards adopted by the organization (Harrison, 1999).

For decision makers, the process of decision-making is not a simple one, where all aspects are within the controlled resources or understood by the individual. Due to the importance of the decisions to the results at individual, organizational and societal level, they are "often subject to the influence of considerations and restrictions of personal, organizational, political and social order” (Mckenna \& Martin-Smith, 2005, p. 821).

According to McCarthy \& Wilson (2001, p. 4), planning and scheduling does not receive divided problems that can be solved optimally by systems. The problems are dynamic and need to be managed all the time. In the oil industry, refineries are the ones that produce the final products, petroleum derivatives. The term refining means the processing of several families of oil received from producing fields and imported to refineries. The desired marketable products are obtained from a set of refining processes.

Among the conversion "plan" of oil into derivatives and the planning and scheduling "plan" there is also what we call operation "plan". In it, there are systems and operators who convert the decisions into processing, transfers and storage in the plant.

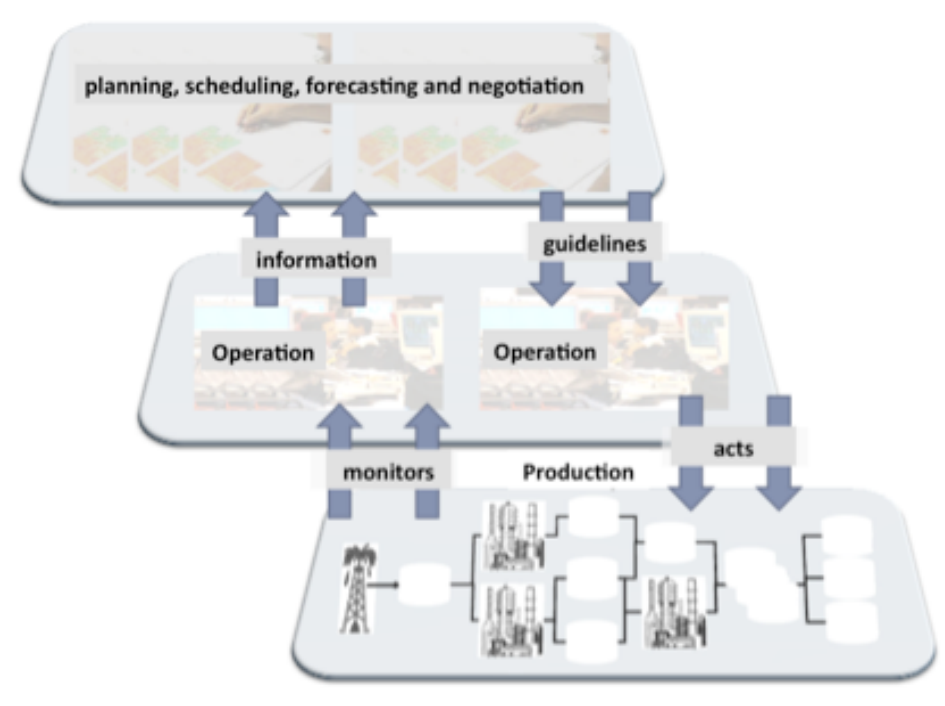

Figure 1. Production system refining plans

Source: the authors.

Figure 1 shows the relationship between the three plans identified. At first, planners and programmers provide guidance to operators. The operators, in turn, under the second plan, operate the production, with the aid of systems according to the directions received. In parallel, Operation monitors what has been done, telling Planning and Scheduling if everything is correct or if there are problems. They analyze the problems and refer new guidelines to operators who work repairing the deviations. 


\subsection{Decision Maker}

The decision maker, no matter how powerful, is not left out of the system as an objective viewer/handler; he or she is a participant in the organization, interacting with other members of that system. As a human being, each member has its own identity and ability to choose (Mckenna \& Martin-Smith, 2005).

According to McCarthy \& Wilson (2001), the field of study in planning and scheduling is widely seen as technical and "solved". However, they indicate that these processes remain significant in organizations and that improvement in practices and achieved outcomes depend on understanding the nature of this process. To the authors, this requires the recognition of the central role of the people who drive these processes in their implementation. After all, they are the ones who manage and solve problems in dynamic environments, and who ultimately "make it happen".

The perception of the problem and/or the allocation of responsibility for solving it belongs to the decision maker. The decision maker is the individual or group that will deal with the problem presented (Marakas, 1998) and therefore some key factors linked to it change how the decision occurs. The number of decision makers as well as the quality and personal preference determines the outcome of the decision making process (Bronner, 1993). The decision makers analyzed in this study are responsible for preparing the scheduling of refinery production.

Decisions are not equal and do not have the same degree of difficulty (Beach, 1997), but they are all dependent on the mental model of their decision makers. Agents can be assessed by individual knowledge about the problem, ability to resolve each problem, his/her wishes and interests, and ethical and moral standards that regulates them (Yang, 2003). By taking a particular decision, the individual makes his/her own interpretations and/or heuristics for such. Thus, the quality of a decision depends not only on the information available, but also on the way in which the decision maker understands this information (Curseu, 2007).

\section{Characterizing the Decision Making Process of Scheduling a Refinery}

The hierarchy between planning and scheduling is evident, including the already mentioned name "hierarchical planning". Viewed from the perspective of the roles, the planner prepares the plan at some aggregated level and programmers realize it in practice. According to McCarthy \& Wilson (2001, p. 8), this "passage” is where many of the problems and conflicts observed in practice are located. Questions such as allocation, assignment, responsibility and authority are raised.

The decision-maker, in order to obtain the information necessary for his/her decision, will interact with other individuals, which in turn will have specific roles in the organization. Yang (2003) presents this as one of the most effective ways of capturing the information necessary for the decision.

In the refineries analyzed, it was observed that the programmer is a profile with strong 'tacit' vector, formed by knowledge based on the production system (history in the refinery). In this 
sense, it seems that the trend in the operation favors the quality of decisions. The experience of these actors shape a certain mental framework that incorporates both good and bad solutions to the types of problems presented. Polya (1957) further states that observing the solution adopted, reconsidering and reviewing the results and impacts caused by it, the decision maker gains a consolidation of knowledge and develops his/her ability to solve problems. Furthermore, no problem is never completely exhausted. With penetration and study about the followed process, one can improve any solution and expand the understanding of the issue.

As an aid to decision-making, programmers use simulators or spreadsheets that once having entered the input data, process this data without an objective function. This means that the system does not generate an optimized result according to criteria that have been previously programmed and fixed, but rather a result that will directly depend on the decision maker. Therefore, it is up to the programmer a complex decision making: he/she shall judge the possible dilemmas that may exist between the criteria of that particular instance, evaluating programming reports that are generated by the simulator and then finalize his/her scheduling.

Given the information and their mental models, decision makers will undertake certain interpretations of the information in question (McKay, 2001, p. 43). Among the characteristics that alter the course of the decision process and therefore the solution generated, Bronner (1993) indicates the interpretative patterns. Kenneth McKay also highlights the use of a set of "rules of hand." Decision makers facing problems; enforce certain relations to react to stimuli. Thus, decisions are a function of the observed variables and rules rather than what hand rules indicate to the decision-maker.

\section{Guidelines for Planning and Decision Making Process of a Refinery Scheduling}

Programming decision levels have general guidelines that must be considered, albeit non-explicitly or in a non-definable way. These guidelines in some cases have technical origin, the type of oil or the characteristics of the refining scheme, in other situations are derived from business, corporate guidelines.

In general, in any refinery it is sought to avoid "shaken" units. That is, frequent changes in operating conditions (defined campaigns for units). When the campaign is changed, the units are taken from the steady state, undergo a transient period until entering stationary regime again. The tankage available determines the decision to change a particular campaign. As for stocks, there is a guideline from the service demand, which guides the existence of a safety stock of finished product. This should ensure meeting the demand of two or three days, if the refinery has any operational problems that prevent it from keeping production. As for the guidance to maintain operational continuity, this is broken down into a policy of intermediate storage. Whereby levels equivalent to the minimum volume to keep the units operational are established.

As general guidelines, one can observe the highlight of minimizing losses resulting from the refining process, according to which decision-makers must always seek to prioritize decisions so as not to generate waste-both oils and derivatives. That is, even in a dynamic 
environment, where there may be many variations over the refining processes, refineries must always converge their decisions trying to accomplish their goals optimally. Additionally, there is a general guideline to keep the refineries operating at full load and to avoid as much as possible to stop units. These criteria, although not always explicit, permeate all decisions made.

Another corporate orientation is the processing of waste and acid oils. The domestic production of oil is classified as acids is growing and the downside of this quality is related to metallurgical constraints (corrosivity) of process units. There is a corporate guideline for the refineries to process the maximum oil acid respecting this limitation. On the other hand, waste (waste streams from the process units) must be reprocessed and are considered in the production plan of all refineries.

\subsection{The Criteria for the Decision of the Programmer}

The following will describe the criteria that are particularly found in decision-making of the refining scheduling.

(i) Meet demand (provided for in the aggregated Plan of the Company);

The concept of meeting the demand expected in the aggregated Plan of the Company is related to the amount of orders of the derivatives market - and their respective volumes -, which will be used as input for the preparation of the plan. Eventually, one can detect additional demand during planning, which will also be considered.

Given this framework, the office responsible for decision making under this criterion should consider the following element:

- Volume of oil to be produced;

- Deadline for order delivery;

- Use of the processing units;

(ii) Meeting the demand (real);

The concept of meeting the real demand refers to the amount of requests from the local derivatives market - and its respective volumes - that will be accepted and met throughout the month, added to the demands supplied by production of the refinery. In practice, consideration of this criterion means to meet, wherever possible, all orders made to the refinery. Given this framework, the office responsible for decision making under this criterion should consider the following element:

- Volume of oil to be produced;

- Deadline for order delivery;

- Use of the processing units; 
(iii) 'Appropriate' oil destination in locked campaigns;

The concept of 'appropriate' oil destination in locked campaigns, or 'efficient use of oil' refers to the best performance that can be achieved given an oil or mixture of oils. That is, from the TBP (True Boiling Point) of the distillation load, which can be obtained in terms of yield and product value. One application of this concept is in how to best mix of oils so that they are used efficiently. Given this framework, the office responsible for decision making under this criterion should consider the following element:

- Processing of oil in distillation units;

(iv) Operate at maximum load;

The concept of "operating at maximum load" refers to the practice of keeping the process units of the refinery running at its maximum capacity. Reducing loads changes operating parameters of the units considered in the drafting process of planning (the use of the optimizer software), which can result in deviations from the plan.

Given this framework, the office responsible for decision making under this criterion should consider the following element:

- Use of the processing units;

- Campaign of the processing units;

- $\quad$ Space in tank;

- Volume of derivatives to be produced;

Currently, the bottleneck of the Company's refineries is located in treatment units. This is due in part to the increased accuracy required in specifications. Operating these units at full load provides increased flexibility for the programmer, increasing the number of possible mixes to adjust products.

(v) Avoiding stops at the units;

The concept of "avoiding stops at the units" refers to the practice of keeping the refinery processing units always running. Given this framework, the office responsible for decision making under this criterion should consider the following element:

- Use of the processing units;

- $\quad$ Space in tank;

- Stocks of intermediate products;

- Volume of derivatives to be produced;

(vi) Classifying products:

The concept of "classifying products" refers to the qualitative characteristics controlled for each derivative. 
It is noteworthy about this criterion the importance of the relationship it has with the use of certain refinery processing units. For products that are classified in the specifications, mixtures and treatments are performed. Products other than those specified may result in the necessity of reprocessing.

Given this framework, the office responsible for decision making under this criterion should consider the following element:

- Use of separation units (because an imbalance can hinder 'future’ specification);

- Use of conversion units;

- Use of treatment units;

- Blending in the line and in tank;

- Tanks for Oil Mixture

- Properties of oils

- Properties of currents produced and storage tanks;

(vii) Reduce give-away;

The concept "reduce give-away" refers to the practice of adding value to products through processing and mixing of currents up to a "point". The aim is to avoid that the final product produced has better qualities than those required for its specification

It is noteworthy about this criterion the importance of the relationship it has with the space in the tank and with certain processing units. Tank space is necessary so one can store finished products (that do not require further processing) and to allow for certain mixtures. Regarding processing units, there are some that stand out as the most critical in the sense of adding value to the products, especially the processing units.

Given this framework, the office responsible for decision making under this criterion should consider the following element:

- $\quad$ Space in tank (flexibility to mix the 'finished' product);

- Use of treatment units (improve the chemical properties);

- Use of conversion units (convert currents into products of greater interest);

- Blending in the line and in tank;

- Properties of the currents

(viii)Meeting the production plan

The concept of "meeting the production plan" regards to compliance with the guidelines of production that are planned and defined monthly. In practice, it is precisely to meet the official plan that is published and approved by the refineries, consuming allocated oils and producing products to meet the demand. A corporate indicator that must be calculated 
monthly measures this.

Given this framework, the office responsible for decision making under this criterion should consider the following element:

- Official production plan;

- Guidelines and guidance from the plan;

- Consumed oils;

- Volume of oil to be produced;

\subsection{Analysis of the Criteria That Guide the Decision of the Programmer}

As stated in the introduction, this work will analyze the relationship between the criteria presented in the previous section. It is noteworthy that, in all cases, the decision of which criteria to prioritize is up to the programmer. Any dilemma that exists in a given situation will directly involve the relevance at the time in question, of each of the criteria involved.

(a) 'Appropriate' destination of oil in locked campaigns X Meeting the demand

These criteria correlate differently, diverging in some occasions and converging in other occasions.

This relationship is evident when one observes the elements that stand out in each of these two criteria: "Processing of oil in distillation units" and "volume of (which) derivatives to be produced” ('appropriate' destination of oil in locked campaigns and meeting the demand, respectively), both of which involve the processing that will lead to the production of final products.

It is usually sought to meet both criteria. However, if there is an urgency to meet the deadlines of certain deliveries, the issue of 'appropriate' destination of oil in locked campaigns will be put in the background. On the other hand, if no such urgency and deadlines are within the agreed limits, it will always be sought to use the oil in order to get better use of its properties.

(b) 'Appropriate' destination of oil in locked campaigns X Operating at maximum load

These criteria correlate in different ways.

This conflict is evident when looking at the elements that stand out in these two criteria: "Processing of oil in distillation units" and "Use of processing units" ('appropriate' destination of oil in locked campaigns and operating at maximum load, respectively).

The dilemma managed by the programmer for these criteria is in extreme situations, for example, having greater benefit in secreting a specific oil for a campaign that cannot be performed when the burden of lowering the unit load or maintaining operation under maximum load assuming the burden of processing an oil with more specific purposes. Among the factors that influence this decision are planning horizon, tankage availability and shipment of product. 
Where refiners do not have space in tank and availability of hardware to operate at full load steadily, a non-optimal utilization of oil is carried out. Some refineries, due to the greater complexity of their hardware, are less sensitive to changes. In these refineries, the concept of 'appropriate' destination of oil in locked campaigns is maximized and does not affect the operation at maximum load.

Moreover, the 'appropriate' destination of oil in locked campaigns can generate a stock level below that required to keep the subsequent units operating at maximum load. There are also other units, such as those producing lubricants and paraffin (high value products), which operate intermittently, with frequent stops due to the availability of load. That is, in this case it inverts the relevance between standards.

(c) 'Appropriate' destination of oil in locked campaigns X Avoiding stops at the units

These criteria correlate in different ways.

This conflict is evident when looking at the elements that stand out in these two criteria: "Processing of oil in distillation units" and "Use of processing units" ('appropriate' destination of oil in locked campaigns and avoiding stops at the units, respectively).

Analogous to the previous analysis, the divergence between these criteria occurs primarily when there is little space available in the tank currents. In this case, the option is to make the worst use oil to prevent the reduction of load units, and, at the limit, it is preferred reduce the load than to stop the unit.

There is also, as mentioned in the foregoing criteria, other units such as those producing lubricants and paraffins, with frequent stops operating due to availability of load. That is, in this case it inverts the relevance between standards.

(d) 'Appropriate' destination of oil in locked campaigns X Classifying products

These criteria are independent.

This relationship is evident when one observes the elements that stand out in these two criteria: "Processing of oil in distillation units" and "tankage for blending oils" and "properties of oil received" ('appropriate' destination of oil in locked campaigns and classifying products, respectively).

It is noteworthy that, for the case of refineries that do not have hardware available to treat products later, mixtures prior to the distillation affect the classification. Thus, they are dependent on the availability of raw materials and available space in tank to perform the mixtures to the "ideal" ratio before separating the currents in the distilling unit (atmospheric and vacuum).

(e) 'Appropriate' destination of oil in locked campaigns X Reducing give-away

These criteria are divergent.

This relationship is evident when one observes the elements that stand out in these two criteria: "Processing of oil in distillation units" and "Properties of currents generated" and 
"Use of treatment units” ('appropriate' destination of oil in locked campaigns and classifying products, respectively), where the reasons for such convergence are explained in the paragraphs below.

Giving an appropriate' destination of oil in locked campaigns can generate currents with properties above the necessary for the classification of the product. In this case, the mixtures performed will then "carry" an over-specification.

If, before the separation of the mixture of oil, there is concern about the reduction in the give-away, the currents obtained are consistent with the specifications, but the 'appropriate' destination of oil in locked campaigns will not have been given.

(f) 'Appropriate' destination of oil in locked campaigns X Meeting the production plan

These criteria correlate variably: there are times when they diverge, and there are times when they converge.

This relationship is evidenced by observing the elements that stand out in these two criteria: "Processing of oil in distillation units" and "consumed oils" and "volumes of derivatives being produced” ('appropriate' destination of oil in locked campaigns and meeting the production plan, respectively).

Refineries always seek to comply with what was agreed in the official production plan that has been assessed and published. For this, there is no problem, at first, to simultaneously process the oils available in order to obtain the best utilizations of its properties, producing certain derivatives. However, there are cases where meeting the plan can lead to less efficient use of oil. Faced with this dilemma, the decision of which to prioritize shall fall upon the position responsible for the level with the probable involvement of headquarters.

(g) Meeting the demand X Operating at maximum load

These criteria correlate variably: there are times when they diverge, and there are times when they converge.

This relationship is evidenced by observing the elements that stand out in these two criteria: "Volume of derivatives to be produced" and "Utilization of processing units."

If there is an urgency to meet the deadlines of certain orders, the issue of the maximum load operation can be put in the background, giving priority to use the hardware to meet the demand. By prioritizing certain currents, one cannot have enough quantities of other currents to keep all units operating at maximum load. After all, so that the maximum load operation is possible, there must be sufficient intermediaries stock to maintain the units operational.

Thus, when the combination of hardware, allocation of oil, stock levels and campaign are such that satisfy to meet the demand, the criteria are convergent.

However, for cases where even meeting the demand, there is an accumulation of one or more products in stock in such amplitude that generates the need to decrease the load, the criteria behave divergently. 
In this situation, the role of the programmer is to find alternatives along with other actors to prevent the decrease of load at the units.

(h) Meeting the demand X Avoiding stops at the units

These criteria correlate variably: there are times when they diverge, and there are times when they converge.

This relationship is evidenced by observing the elements that stand out in these two criteria: "Volume of derivatives to be produced" and "Utilization of processing units."

A review of the stop of a unit is always the maximum limiting condition. This implies that before a possible stop all criteria and alternatives will be considered to avoid it.

Stops of units not covered by the annual maintenance plan only occur due to lack of availability of raw materials, space constraint in stock for a particular product or intermediary, or a serious operational problem. Thus, situations could arise in which one chooses to perform certain changes in processing (decreased load, use of certain current for alternative purposes, reprocessing) that do not necessarily lead to meeting the market demands, but avoid stops.

(i) Meeting the demand X Classifying products

These criteria are convergent.

This relationship is evidenced by observing the elements that stand out in each of these two criteria: "Volume of (which) derivatives to be produced" and "Use of conversion units and treatment" (meeting the demand and classifying products, respectively), both of which involve the processing that will lead to the production of final products, with the reasons such for convergence explained in the following paragraphs.

Refiners cannot meet the demand with products out of specification. Moreover, there is no conflict to fulfill these two criteria.

(j) Meeting the demand X Reducing give-away

These criteria correlate variably: there are times when they diverge, and there are times when they converge.

This relationship is evidenced by observing the elements that stand out in each of these two criteria: "Volume of (which) derivatives to be produced" and "Use of treatment units" (meeting the demand and reducing give-away, respectively), both of which involve the processing and activities that will lead to the production of final products.

It is usually sought to meet both criteria. However, if there is a need to meet the deadlines of certain orders, the issue of the reduction of the give-away will be put in the background. Nevertheless, if there is not this need and deadlines are within the agreed limits, it will always be sought to avoid give-away.

One should also consider the availability in tank or currents that can be mixed to reduce 
give-away. On certain occasion, even with urgent delivery, if there is this availability, the give-away can be reduced or even eliminated.

(k) Meeting the demand X Meeting the production plan

These criteria correlate variably: there are times when they diverge, and there are times when they converge. The decision on which one to prioritize therefore belongs to the office responsible for this level.

This relationship is evidenced by observing the elements that stand out in these two criteria: "volume of (which) derivatives to be produced" where the reasons for this dilemma have been explained in the paragraphs below.

Refiners always seek to meet two criteria, fulfilling what was established in the official production plan that has been assessed and published taking into account a given forecast of market demand.

However, there are systematics that allow customers to change the quotas of requests for derivatives. Therefore, as much as one always seeks to meet the plan, with extra-quota approved and the possibility of their delivery, refineries will produce to meet the current demands of its customers.

It can therefore be affirmed that, essentially, the purpose of these two criteria is the same, but there are temporal differences about the information used.

(l) Operating at maximum load X Avoiding stops at the units

These criteria correlate variably: there are times when they diverge, and there are times when they converge.

Usually one tries to meet two criteria. Considering that every product produced and specified is consumed, the criteria relate to convergence: the oils are processed at maximum load and in this context; it is inherent to the idea of avoiding stops at the units.

Conditions of low supply of raw materials or high inventory of intermediate/final product may lead to the need to reduce the load of the units to prevent its stops. In this context, the criteria are different.

(m) Operating at maximum load X Classifying products

These criteria correlate variably: there are times when they diverge, and there are times when they converge.

This relationship is evidenced by observing the elements that stand out in each of these two criteria: "Use of the processing units" and "use of conversion units and treatment" (operating at maximum load and classifying products, respectively), where the reasons for this dilemma are explained in the paragraphs below.

These are convergent if the currents produced and the products in tanks are such that they conform to the specifications. However, if the products for some reason are not classified - a 
hardware problem of a unit, or some unexpected chemical reaction - it becomes a waste operate to a maximum load to generate products that will need to be reprocessed later.

In case of unavailability of tanks or large amount of off-specification product one can opt for reprocessing or, if this is not possible, decreasing load.

(n) Operating at maximum load X Reducing give-away

These criteria are divergent. This conflict is evident when looking at the elements that stand out in these two criteria: "Use of the processing units" and "use of conversion units and treatment” (operating at maximum load and reducing give-away, respectively), where the reasons for this dilemma are explained in the paragraphs below.

Although refineries always seek to meet two criteria, and that this possibility exists, their essences are divergent: Forcing the refinery processing to maximum load is a criterion that conflicts with the worry of adding value to products through processing only in cases where there is specific need. Therefore, one can consider them divergent

If there is generation of a product with over-spec beyond what the hardware is capable of absorbing, a possible alternative would be to reduce the load of the processing unit. However, currently this is not followed; it is then decided for the sale with over-specification.

(o) Operating at maximum load X Meeting the production plan

These criteria correlate variably: there are times when they diverge, and there are times when they converge. The decision on which one to prioritize therefore belongs to the office responsible for this level.

This relationship is evidenced by observing the elements that stand out in these two criteria: "volume of (which) derivatives to be produced" where the reasons for this dilemma have been explained in the paragraphs below.

With respect to the plan, there is a large corporate dilemma, because even if the aggregated plan of the Company indicates that the refinery is operating below maximum capacity, the guidance received from other areas of the company is that one should always operate at maximum load. Thus, it can be stated that the management of these two criteria is convergent only when the production plan also indicates operation at maximum load. If this assumption is not met, the criteria are present divergently.

(p) Avoiding stops at the units X Classifying products

These criteria correlate independently. Refineries always seek to meet two criteria, that the products to be delivered to clients must comply with the applicable specifications. Avoiding stops at the units, at first, does not interfere or create conflicts with this issue. The greater the number of conversion units and treatment, the greater the flexibility of the refinery to classify products.

The decision to stop the unit is the last alternative among others. Thus, all criteria and alternatives will be considered to avoid it. Therefore, it does not occur at the expense of the 
classification of products.

It is noteworthy that, before an operational stop, i.e. when there is no possibility of avoiding it, how the product will be classified (specification) becomes an even more important point.

(q) Avoiding stops at the units X Reducing give-away

These criteria correlate variably: there are times when they diverge, and there are times when they converge. The decision on which one to prioritize therefore belongs to the office responsible for this level.

This conflict is evident when looking at the elements that stand out in these two criteria: "Use of the processing units" and "use of conversion units and treatment" (avoiding stops at the units and reducing give-away, respectively), where the reasons for this dilemma are explained in the paragraphs below.

Depending on the production portfolio of the refinery and the available hardware (units and tanks) reducing give-away and avoiding stops until they are independent units to maintain production levels is the best loss of value through delivering product over-specification.

Note that stopping a given unit is an extreme decision when there is no available space in the tank for product, no availability of raw materials or due to an operational problem.

However, depending on the unit stopped, the resulting currents that are generated can be presented as over or under-specification. Thus, one can increase or decrease the give-away, respectively. Therefore, these two criteria can converge or diverge, ranking as variables.

(r) Avoiding stops at the units X Meeting the production plan

These criteria correlate variably: there are times when they diverge, and there are times when they converge. The decision on which one to prioritize therefore belongs to the office responsible for this level.

This relationship is evidenced by observing the elements that stand out in these two criteria: "volume of (which) derivatives to be produced" where the reasons for this dilemma have been explained in the paragraphs below.

The programmer is trying to meet the production plan and not program stops that are not provided for by the production plan and in this sense, the criteria are converging. However, if a low storage capacity generates the need to lower the production of a certain current, the programmer has the option to lower the load to avoid stop a unit. In this case, the criteria are different and avoiding a stop is prioritized in relation to meeting the programmed plan (a few days).

(s) Classifying products X Reducing give-away

These criteria are divergent. This relationship is evident when observing the deviation of the elements that stand out in these two criteria: "Use of treatment units" and "blending in the line and in tank" where the reasons for such convergence are explained in the paragraphs below. 
Usually one tries to meet two criteria. However, all products produced by the refinery should be in accordance with applicable specifications. For this, one always seeks to work with a confidence interval that can guarantee that production will be classified. In this perspective, however much they seek to avoid give-away making a mixture, there is always a tendency to over-specification so that it can reduce the chances that derivatives produced do not fit the specifications.

(t) Classifying products X Meeting the production plan

These criteria are convergent.

This relationship is evident when observing the convergence of elements that stand out in these two criteria, where the reasons for such convergence are explained in the paragraphs below.

Refineries can never meet the plan with out of specification products. Moreover, there is no conflict to fulfill these two criteria. Thus, one can consider that both have the same guideline, walking together towards the same direction.

(u) Reducing give-away X Meeting the production plan

These criteria correlate variably: there are times when they diverge, and there are times when they converge.

This relationship is evidenced by observing the elements that stand out in each of these two criteria: "use of treatment units" and "volume of (which) derivatives to be produced" (reducing give-away and meeting the production plan), since both involve the processing that will lead to the production of final products.

The dilemma that exists in this situation will directly involve the relevance of each of these criteria depending on the case. Usually one tries to meet two criteria. If there is an urgency to fulfill deliveries of product, the issue of the decline of the give-away will be put in the background, and efforts will focus on meeting them, which is reflected in meeting the plan. However, if there is this need, one will always seek to avoid give-away.

In preparing the Production Plan, the availability in the tank or the availability of currents that can be mixed to reduce the give-away must have already been considered.

\section{Considerations about the Trade-Offs that Are Presented the Programmer of a Refinery}

Throughout the article, an analysis, summarized in Table 1, with considerations for each criterion of the production program, and their relations in pairs was presented. The rankings in the table follow this 'scale' of consistency between the criteria. Criteria are divergent when proposing guidelines for at least one (1) element of the decision obligatorily go towards the opposite direction to each other. That is, on the occasion of two divergent criteria, by fulfilling one of them, the other is suppressed. Criteria are divergent when proposing guidelines for at least one (1) element of the decision obligatorily go towards the opposite direction to each other. That is, if two criteria are converging, the two criteria may also be 
adopted and together drive the decision to their goal. Criteria correlate variably when there are they diverge or converge. The dilemmas of the decision on what to prioritize shall fall upon the office responsible for this level.

Table 1. Cross-analysis of the criteria

\begin{tabular}{|l|l|l|l|l|l|l|}
\hline & $\begin{array}{l}\text { Meeting the } \\
\text { demand }\end{array}$ & $\begin{array}{l}\text { Operating at } \\
\text { maximum } \\
\text { load }\end{array}$ & $\begin{array}{l}\text { Avoiding } \\
\text { stops at the } \\
\text { units }\end{array}$ & $\begin{array}{l}\text { Classifying } \\
\text { products }\end{array}$ & $\begin{array}{l}\text { Reducing } \\
\text { give-away }\end{array}$ & $\begin{array}{l}\text { Meeting } \\
\text { production plan }\end{array}$ \\
\hline $\begin{array}{l}\text { 'Appropriate' } \\
\text { destination of oil in } \\
\text { locked campaigns }\end{array}$ & Variable & Divergent & Divergent & Independent & Divergent & Variable \\
\hline $\begin{array}{l}\text { Meeting the demand } \\
\text { Operating at maximum } \\
\text { load }\end{array}$ & Variable & Variable & Convergent & Variable & Variable \\
\hline $\begin{array}{l}\text { Avoiding stops at the } \\
\text { units }\end{array}$ & & Variable & Variable & Divergent & Variable \\
\hline $\begin{array}{l}\text { Classifying products } \\
\text { Reducing give-away }\end{array}$ & & & & Independent & Variable & Variable \\
\hline $\begin{array}{l}\text { Meeting } \\
\text { production plan }\end{array}$ & & & & Divergent & Convergent \\
\hline
\end{tabular}

Source: the authors.

As it can be seen, only two combinations of criteria are not always convergent and do not demand an analysis and particular solution of the programmers. It was observed from the analysis of the refineries studied that the set of variables to be considered is large, and that in many situations the space of divergence between guidelines is large. This scenario requires a complex decision making from the programmer. Programmers, while decision makers of the production of their respective refineries, will have to resort to interpretive standards (formed throughout their history in the refinery, the implied vector which this article previously mentioned) and judge the possible dilemmas that may exist between criteria in a particular situation. After a program proposal is formulated for production, programmers assess it from their mental picture, and decide to follow with that solution or to seek a new solution, i.e., a new referral to the conflicts that emerge between the criteria.

In order to minimize the space required for reconciliations between guidance that arise to the programmer, it is proposed to follow a standard sequence for the first composition of program proposal. Initially, as a working hypothesis, the production plan 'solves' the contradictions in the previous hierarchical level, and thereafter, shall be followed by the scheduling. In this sense, it indicates that the 'unexpected events' are treated to, on average, follow the solution generated in the planning. 
Regarding the guidelines that 'conform' the decision of the programmer, one can (in simplification) sequence them as follows:

- Classifying products (as 'primary' restriction, it is usually a requirement to meet the demand.)

- $\quad$ Meeting the demand (real)

- Operating at maximum load (i.e., the load defined in the plan. A 'concern' that arises from it appears in this quest for operational stability.)

- Avoiding stops at the units

- 'Appropriate’ destination of oil in locked campaigns

- Reducing give-aways

Among some of the working hypotheses that can be considered for scheduling, there are available in the market and not explored in the current study, a range of computational solutions that support the "resolution" of the dilemmas discussed above. Thus, one might think, for example, in simulators that help the programmer to test scenarios and determine which solution would be obtained before the prioritization of other criteria.

\section{References}

Beach, L. (1997). The Psychology of Decision Making: People in Organizations. California: SAGE Publications. http://dx.doi.org/10.4135/9781452204406

Berthoz, A. (2006). Emotion and Reason: The Cognitive Neuroscience of Decision Making. New York, Oxford University Press.

Bronner, R. (1993). Decision Making in Complex Situation, Management International Review, 33, 7-25.

Corrado, G. S., Sugrue, L. P., Brown, J. R., \& Newsome, W. T. (2008). The Trouble with Choice: Studying Decision Variables in the Brain. In P. W. Glimcher, C. Camerer, R. A. Poldrack, \& E. Fehr (Eds.), Neuroeconomics: Decision Making and the Brain (pp. 463-480). Academic Press. http://dx.doi.org/10.1016/b978-0-12-374176-9.00030-0

Corrêa, H. (2001). Planejamento, Programação e Controle da Produção com MRPII / ERP: Conceitos, Uso e Implantação. São Paulo: Atlas.

Curseu, P. L., \& Vermeulen, P. A. M. (2008). Entrepreneurial Strategic Decision-Making: A Cognitive Perspective. Edward Elgar Publishing. http://dx.doi.org/10.4337/9781848444034

Harrison, E. F. (1999). The Managerial Decision-making Process. Boston, MA, Houghton.

Hastie, R., \& Pennington, N. (1995). Cognitive approaches to judgment and decision making. In J. Busemeyer \& R. Hastie (Eds.), Decision Making from a Cognitive Perspective (pp. 1-31). Academic Press. http://dx.doi.org/10.1016/s0079-7421(08)60306-0

Maccarthy, B., \& Wilson, J. R. (2001). Human Performance in Planning and Scheduling. 
CRC.

Marakas, G. (1998). Decision Support Systems in the 21st Century: DSS and data mining technologies for tomorrow's manager. Nova Jersey: Prentice Hall.

Mckay, K. (2001). In B. Maccarthy \& J. R. Wilson (Orgs.), Human Performance in Planning and Scheduling. CRC.

Mckenna, R. J., \& Martin-Smith, B. (2005). Decision making as a simplification process: new conceptual perspectives. Management Decision, 43(6), 821-836. http://dx.doi.org/10.1108/00251740510603583

Mykytyn, P. (1985). Effects of cognitive style and task structure on decision making with a DSS (Support Systems). Tese de Ph. D., Arizona State University.

Ofstad, H. (1961). An inquiry into the freedom of decision. Oslo: Norwegian Universities Press.

Payne, J., Bettman, J., \& Johnson, E. (1993). The Adaptive Decision Maker. Nova York, Cambridge University Press. http://dx.doi.org/10.1017/CBO9781139173933

Polya, G. (1957). How to Solve It (2nd ed.). Princeton University Press: New Jersey.

Shull, F. A., Delbecq, A. L., \& Cummings, L. L. (1970). Organizational decision making. New York, McGraw-Hill.

Simon, H. A. (1960). The new science of management decisions. New York, Harper and Row.

Svenson, O. (1996). Decision Making and the Search for Fundamental Psychological Regularities: What Can Be Learned from a Process Perspective? Organizational Behavior and Human Decision Processes, 65(3), 252-267. http://dx.doi.org/10.1006/obhd.1996.0026

Yang, B. (2003). Political Factors in Decision Making and Implications for HRD. Advances in Developing Human Resources, 5(4), 458-479. http://dx.doi.org/10.1177/1523422303257289

\section{Copyright Disclaimer}

Copyright for this article is retained by the author(s), with first publication rights granted to the journal.

This is an open-access article distributed under the terms and conditions of the Creative Commons Attribution license (http://creativecommons.org/licenses/by/3.0/). 